\title{
Comparison between manual scaling and Autoscala automatic scaling applied to Sodankylä Geophysical Observatory ionograms
}

\author{
Carl-Fredrik Enell ${ }^{1}$, Alexander Kozlovsky ${ }^{2}$, Tauno Turunen ${ }^{2, *}$, Thomas Ulich ${ }^{2}$, Sirkku Välitalo $^{2}$, Carlo Scotto $^{3}$, and \\ Michael Pezzopane ${ }^{3}$ \\ ${ }^{1}$ EISCAT Scientific Association, Kiruna, Sweden \\ ${ }^{2}$ Sodankylä Geophysical Observatory, University of Oulu, Sodankylä, Finland \\ ${ }^{3}$ Istituto Nazionale di Geofisica e Vulcanologia (INGV), Rome, Italy \\ * retired \\ Correspondence to: Carl-Fredrik Enell (carl-fredrik.enell@eiscat.se)
}

Received: 16 November 2015 - Published in Geosci. Instrum. Method. Data Syst. Discuss.: 21 December 2015

Revised: 14 March 2016 - Accepted: 14 March 2016 - Published: 23 March 2016

\begin{abstract}
This paper presents a comparison between standard ionospheric parameters manually and automatically scaled from ionograms recorded at the high-latitude Sodankylä Geophysical Observatory (SGO, ionosonde SO166, $64.1^{\circ}$ geomagnetic latitude), located in the vicinity of the auroral oval. The study is based on 2610 ionograms recorded during the period June-December 2013. The automatic scaling was made by means of the Autoscala software. A few typical examples are shown to outline the method, and statistics are presented regarding the differences between manually and automatically scaled values of F2, F1, E and sporadic $\mathrm{E}\left(\mathrm{E}_{\mathrm{s}}\right)$ layer parameters.

We draw the conclusions that:
\end{abstract}

1. The F2 parameters scaled by Autoscala, foF2 and $\mathrm{M}(3000) \mathrm{F} 2$, are reliable.

2. F1 is identified by Autoscala in significantly fewer cases (about $50 \%$ ) than in the manual routine, but if identified the values of foF1 are reliable.

3. Autoscala frequently (30\% of the cases) detects an E layer when the manual scaling process does not. When identified by both methods, the Autoscala E-layer parameters are close to those manually scaled, foE agreeing to within $0.4 \mathrm{MHz}$.

4. $\mathrm{E}_{\mathrm{s}}$ and parameters of $\mathrm{E}_{\mathrm{s}}$ identified by Autoscala are in many cases different from those of the manual scaling. Scaling of $\mathrm{E}_{\mathrm{s}}$ at auroral latitudes is often a difficult task.

\section{Introduction}

Ionosondes for studying the ionosphere were invented in the late 1920s, and their worldwide implementation started in the 1940s as military shortwave communication became important. An ionosonde is a radio echo instrument transmitting radio waves of alternating frequency, receiving reflections from the ionosphere, and measuring the travel times of the waves at different frequencies. The return power vs. frequency and travel time is presented as graphs called ionograms, from which information on the structure of the ionosphere can be derived. The travel times $\Delta t$ are presented as virtual heights $\mathrm{h}^{\prime}=\frac{c \Delta t}{2} ;$ the true reflection heights are different due to the significant radio-wave refraction close to the critical ionospheric plasma frequencies. Up to four distinct layers, called the $\mathrm{D}, \mathrm{E}, \mathrm{F} 1$ and $\mathrm{F} 2$ regions, respectively, in increasing altitude order, can be identified in ionograms, depending on location, season and time of day.

Historically, the shapes of ionograms are described by a number of standard parameters (Piggott and Rawer, 1978). This is useful in order to characterise the main features of the ionosphere, such as what frequencies are usable for long distance communication. These parameters have been read out manually at several observatories since the 1950 s, a procedure referred to as ionogram scaling. Thus, time series of continuous ionospheric observations span several solar cycles, and in order to monitor long-term environmental changes these observations must be continued in a consistent way without significant methodological changes. How- 
ever, manual scaling of ionograms requires substantial work efforts and the results are subjective, so development of automatic scaling routines has started and progressed together with recent developments in computer performance.

One such routine is Autoscala (Pezzopane and Scotto, 2005), which has been developed at the Italian National Institute of Geophysics and Volcanology (INGV) in Rome. Autoscala is a program able to perform an automatic scaling of vertical soundings, giving as output the main ionospheric characteristics (Pezzopane and Scotto, 2007, 2008, 2010; Scotto and Pezzopane, 2007, 2008; Scotto et al., 2012) and an estimation of the electron density profile (Scotto, 2009). It is based on an image recognition technique and can run without polarisation information, which allows the algorithm to be applied to any kind of ionosonde (Pezzopane et al., 2010).

Autoscala works by defining a set $S$ of $N$ pairs of empirical curves $S \equiv\left\{T_{i[\mathrm{o}]}, T_{i[\mathrm{x}]}\right\}, i=1,2, \ldots, N$, fitting the typical shape of the F2 ordinary and extraordinary traces. For each pair of curves $T_{i[\mathrm{o}]}, T_{i[\mathrm{x}]}$ the local contrast $C$ with the recorded ionogram is calculated, making allowance for both the number of matched points and their amplitude. The pair of curves $T_{i[\mathrm{o}]}, T_{i[\mathrm{x}]}$ having the maximum value of $C$ is then selected. If this value of $C$ is greater than a fixed threshold $C_{\mathrm{t}}$, the selected curves are considered as representative of the traces. The values of the critical frequencies are thus obtained from the selected curves. If $C$ does not exceed $C_{\mathrm{t}}$, the routine assumes that the $\mathrm{F} 2$ trace is not present on the ionogram. With a similar procedure, the $\mathrm{F} 1$ and $\mathrm{E}_{\mathrm{S}}$ traces are also detected.

The accuracy of the Autoscala output has been tested against manually validated data at low and middle latitudes. Specifically, the low-latitude stations considered to test Autoscala were those of Tucumán $\left(26.9^{\circ} \mathrm{S}, 294.6^{\circ} \mathrm{E}\right)$, Argentina (Pezzopane et al., 2007), and São João do Cariri (7.5 $5^{\circ}, 323.8^{\circ} \mathrm{E}$ ), Brazil (Scotto and MacDougall, 2012). The corresponding results showed that the abilities of Autoscala are fairly good and reliable, except for the cases of ionograms characterised by the presence of F1.5 or F3 layers, as was illustrated by Scotto (2009).

The mid-latitude stations considered to test Autoscala were those of Rome $\left(41.8^{\circ} \mathrm{N}, 12.5^{\circ} \mathrm{E}\right)$ and Gibilmanna $\left(37.9^{\circ} \mathrm{N}, 14.0^{\circ} \mathrm{E}\right)$, Italy (Pezzopane and Scotto, 2004, 2005, 2007, 2008; Scotto and Pezzopane, 2007), Moscow (55.5 N, $37.5^{\circ} \mathrm{E}$ ), Russia (Krasheninnikov et al., 2010), Warsaw $\left(52.2^{\circ} \mathrm{N}, 21.1^{\circ} \mathrm{E}\right)$, Poland (Pezzopane et al., 2008, 2010), Delaware $\left(43.0^{\circ} \mathrm{N}, 278.8^{\circ} \mathrm{E}\right)$, Canada (Scotto and MacDougall, 2012) and Boulder (40.0 $\left.{ }^{\circ} \mathrm{N}, 105.3^{\circ} \mathrm{W}\right)$, Colorado, USA (Bullett et al., 2010). The corresponding results showed that the output given by Autoscala is reliable and accurate and, at times, better than that given by the Automatic RealTime Ionogram Scaling with True-height (ARTIST) system (Reinisch et al., 2009; Galkin and Reinisch, 2008; Pezzopane and Scotto, 2005, 2007).

Experience from high-latitude stations, including the two different automatically scaling ionosondes at the EISCAT transmitter site at Ramfjordmoen, Norway $\left(69^{\circ} \mathrm{N}\right.$ latitude), a Dynasonde (Rietveld et al., 2008) and a Digisonde (see e.g. Reinisch et al., 2009), shows that in the auroral zone automatically scaled parameters may differ significantly. These two instruments, however, use quite different echo detection and selection techniques and the results depend much on how noise and interference are rejected.

The present comparison is based on ionograms from the ionosonde at the Sodankylä Geophysical Observatory (SGO, $\left.67^{\circ} \mathrm{N}, 26^{\circ} \mathrm{E}, 64.1^{\circ} \mathrm{CGMLAT}\right)$. In contrast to the two instruments above, the SGO ionosonde is a so-called chirp sounder. This technique is based on a continuous wave $(\mathrm{CW})$ transmission of increasing frequency instead of radar pulses.

\section{The Sodankylä ionosonde}

Ionosondes have been running at SGO, URSI station SO166, since the International Geophysical Year 1957. The present ionosonde, called Alpha Wolf, is the third instrument in order and was installed in 2005. Details of the instrument have also been described in Kozlovsky et al. (2013). The Alpha Wolf is a frequency modulated continuous wave (FM CW) chirp sounder developed at SGO. The FM CW chirp technique implies that transmission and reception must be simultaneous, so the transmitting and receiving antennas are separated by approximately $1 \mathrm{~km}$. The transmitter antenna is a rhombic wide-band loop. At the receiver site an array of crossed magnetic loop antennas is installed in order to provide imaging capabilities. However, during these tests the signals from all antennas were combined into two channels, one per linear polarisation. The transmitter and receiver are completely separate systems, starting on the same full second by GPS synchronisation. The exciter of the transmitter and the local oscillator of the receiver are basically identical, producing identical frequency sweeps at a constant rate (chirps). The name Alpha Wolf derives from the distinct "howling" sound produced when the down-converted received signal is fed to a loudspeaker. After mixing and filtering, the base-band converted signal is digitised into data streams of in-phase and quadrature channels, in total four real vectors or one complex signal per polarisation. The conversion from complex sampled data to ionograms is simple: because of the linear frequency sweep, the frequency spread around the centre frequency at each instant in time corresponds to an interval of range (virtual height). The ionograms are thus obtained by applying a windowed fast Fourier transform (FFT) to the digital signal after combining the linearly polarised data into the $\mathrm{O}$ - or X-mode circular polarisation. The centre time of the FFT window gives the centre frequency and the length of the window determines the range resolution, both determined by the frequency sweep rate. The selection of length and overlap of the FFT windows thus implies a tradeoff between frequency and range resolution. The ionograms in this paper were produced with an FFT window length of 4096 points 


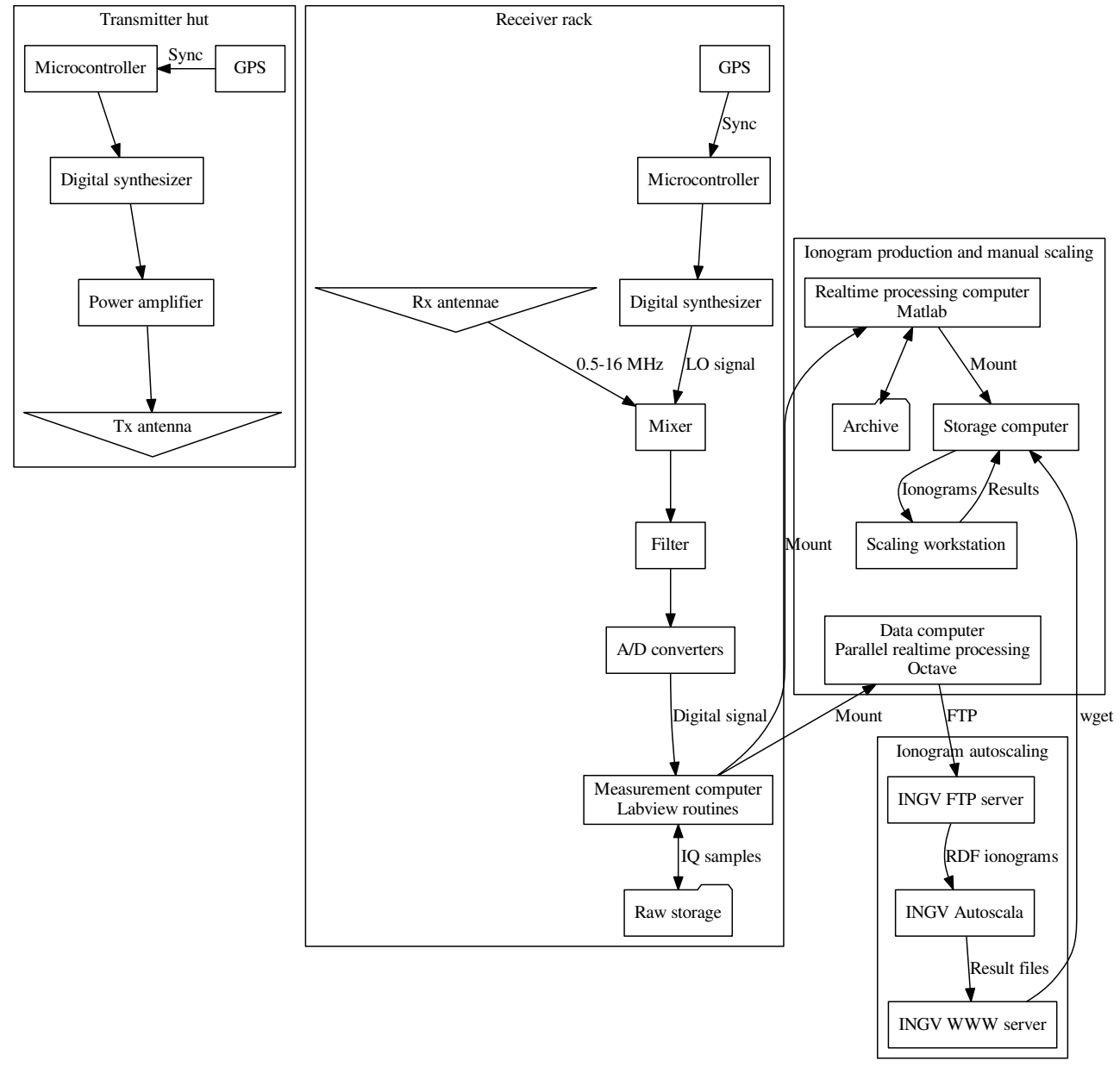

Figure 1. Simplified schematic diagram of the SGO ionosonde system and data flow. Note that the transmitter and receiver station are separated by almost $1 \mathrm{~km}$ and have no direct electronic connection. Transmission and reception of the FM CW chirps both start by GPS synchronisation. Left column: schematics of transmitter station with exciter (direct digital synthesizer) and power amplifier. Filters are not shown. The transmitter feeds a wide-band rhombic antenna. Centre column: schematics of one receiver channel. Signals from all receiver antennas are combined into two channels, one per polarisation. The local oscillator is identical to the exciter. Raw data are saved in binary files containing four real (or two complex) vectors: two linear polarisations, samples of in-phase and quadrature-mixed filtered signals. Right upper: the real-time processing computer reads the raw data, combines the polarisations into O-mode circular polarisation (applying phase corrections), and produces ionograms. O-mode ionograms are stored and those from each full hour are interpreted manually. Right lower: during the described test phase, $\mathrm{O}$ - and X-mode ionograms were uploaded to INGV in the raw data format (RDF) required by Autoscala.

and thus the length of the alias-free virtual height scale is up to 2048 points. Subintervals limited to a maximum of 760 or $1500 \mathrm{~km}$ are shown in the figures. Interference from known shortwave transmitters may be filtered out in the process.

Figure 1 shows a simplified block diagram of the whole system including data processing. The receiver computer reads the digital signals from the A/D converter of the receiver and stores the data temporarily as binary files. These data are then made available to the processing computers through the local network. Most important of those computers is the operational real-time processing computer. Its analysis software, a single Matlab script, produces O-mode ionograms, which are archived and also available online in real time.

\section{Manual scaling of ionograms}

The Sodankylä ionosonde ionograms have been interpreted manually since the start in 1957. Until the deployment of the present system in 2005, the ionograms were recorded and scaled on photographic film. For consistency in the time series of scaled parameters, the present system is designed to present the ionograms to the scaler in a similar manner. Realtime ionograms are copied through the local network and backed up on a dedicated ionogram server, from which they are read and interpreted on the desktop workstation of the scaler. Matlab software running on this workstation displays the O-mode ionograms (see an example in Fig. 2, top panel) and aids the scaler (in this work: coauthor S. Välitalo) to read 

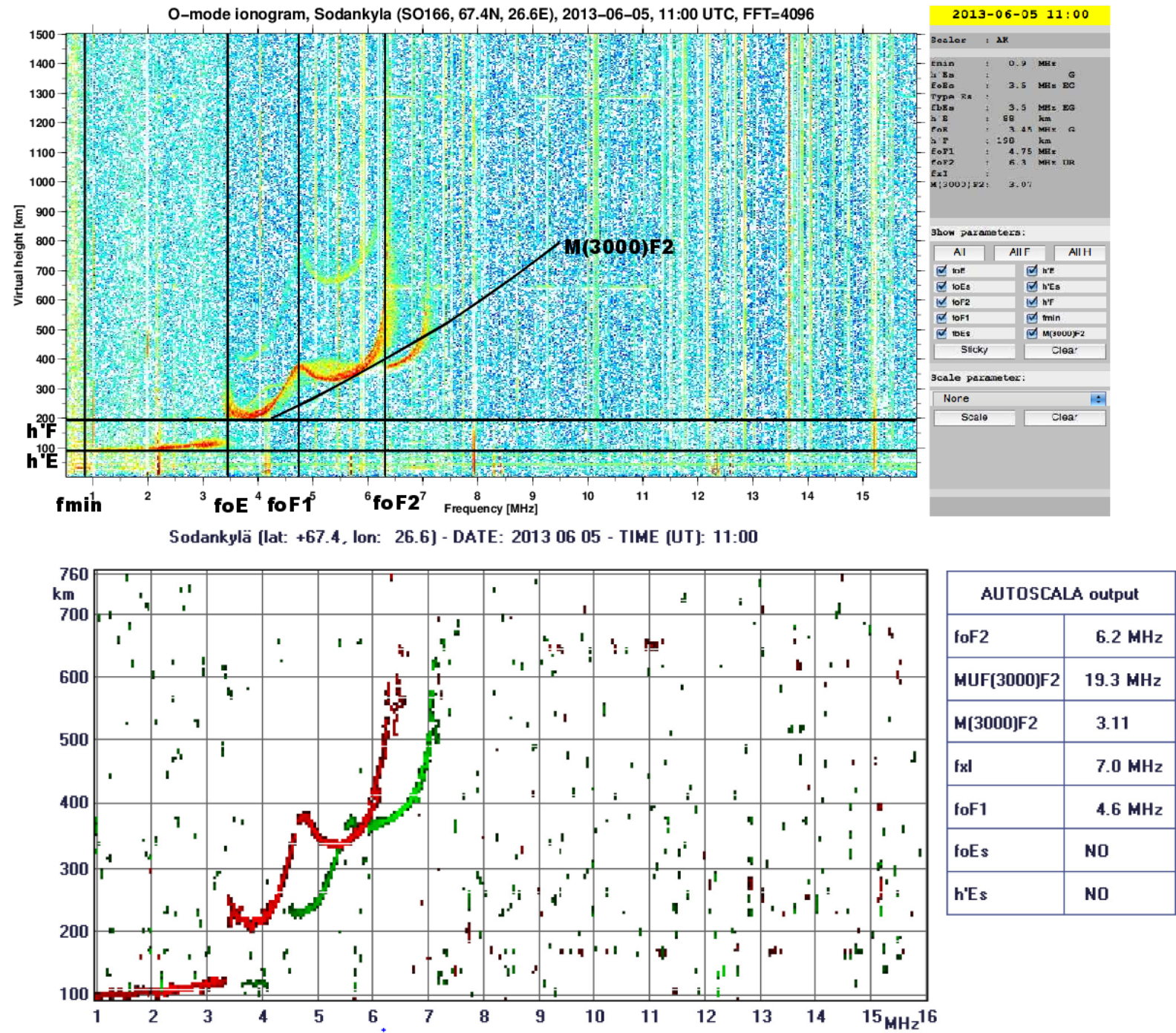

Figure 2. Example of SGO ionogram scaling. Upper: manual scaling interface with a typical Alpha Wolf O-mode ionogram (5 June 2013, 11:00 UT). Colours in the ionogram represent reflected power from 20 (blue) to $110 \mathrm{~dB}$ (red). This colour scale is not used directly by the scaler but is adjustable for best contrast. Lower: graphical output of Autoscala, input based on the same raw data but with separated, filtered O-mode (red) and X-mode (green) traces. The boxes in the right panels show the scaled parameters as described in the text.

out the parameters and save their values. The 11 parameters listed below are routinely scaled once per hour according to Piggott and Rawer (1978) and Wakai et al. (1987). Additionally ionograms at half hours (full hours $+30 \mathrm{~min}$ ) are scaled for critical frequencies (i.e. excluding the virtual heights).

\subsection{Scaled parameters}

- $f_{\min }$ is the lowest frequency of reflected waves recorded in the ionogram.

- foE is the ordinary polarisation mode critical frequency of the lowest thick stratification in the $\mathrm{E}$ region.

$-\mathrm{h}^{\prime} \mathrm{E}$ is the minimum virtual height of the normal $\mathrm{E}$ layer.
- Type $E_{s}$ is the classification of sporadic $E$ layers $\left(E_{s}\right)$, i.e. all those thin, reflecting layers observed in the height range $100-170 \mathrm{~km}$ which are not part of the normal Eand F-layer trace (more details are given in Sect. 5.2).

- $\mathbf{f o E}_{\mathrm{s}}$ is the top frequency of the ordinary wave component of continuous $\mathrm{E}_{\mathrm{S}}$ traces.

$-\mathbf{h}^{\prime} \mathbf{E}_{\mathrm{s}}$ is the lowest virtual height of the trace from which $\mathrm{foE}_{\mathrm{s}}$ is scaled.

- $f b E_{s}$ is the blanketing frequency of the $E_{s}$ layer, i.e. the lowest frequency at which the $\mathrm{E}_{\mathrm{s}}$ layer allows reflections from higher layers. 
- $\mathrm{h}^{\prime} \mathrm{F}$ is the virtual height of the $\mathrm{F}$ layer, i.e. the lowest virtual height of the F-layer ordinary mode trace.

- foF1 is the ordinary mode critical frequency of the F1 layer (which is formed during the daytime mainly in summer at heights above $150 \mathrm{~km}$ ).

- foF2 is the ordinary mode critical frequency of the highest stratification in the $\mathrm{F}$ region.

- M(3000)F2 is the $M$ factor (maximum usable frequency factor), which is a conversion factor for obtaining the maximum usable frequency MUF(3000)F2 for oblique propagation to a distance of $3000 \mathrm{~km}$ with reflection from the F2 layer, i.e. $\operatorname{MUF}(3000) \mathrm{F} 2=\mathrm{M}(3000) \mathrm{F} 2 \times$ foF 2 . The $\mathrm{M}$ factor depends on the virtual height of the F2 layer and can be approximated based on a simplified propagation model as detailed in Piggott and Rawer (1978). This approximate $\mathrm{M}$ factor ranges between 2.04 at $800 \mathrm{~km}$ and up to 4.55 at $200 \mathrm{~km}$, typically close to 3 for normal F2 heights. In practice, sets of curves of constant MUF(3000)F2 in the frequency-height plane are calculated. The curve tangential to the F2 trace is selected and gives MUF and the M factor as shown in the upper panel of Fig. 2.

The six parameters indicated in bold face in the above list are those automatically scaled by Autoscala. Their values are compared in the following.

\section{Automatic scaling}

Autoscala works using input ionograms in a specific binary RDF Pezzopane and Scotto (2005), in which O- and X-mode traces are saved separately. Hence, in order to apply Autoscala to the ionograms recorded by the SGO ionosonde, a change of file format was required. During the Autoscala test phase presented here, a second set of real-time ionogram processing software was therefore installed on a separate computer in order to produce the required $\mathrm{O}$ - and $\mathrm{X}$-mode traces. A modified and improved version of the real-time analysis software was used, running under the open source Matlab-compatible language Octave (Eaton et al., 2015). In order to improve the contrast of the $\mathrm{O}$ - and $\mathrm{X}$-mode traces, an improved filtering to mask out weak echoes was applied when converting the data to ionograms. This filtering may be necessary in order for the automatic scaling to find the normal E- and F-layer ionogram traces, but as will be seen it may also mask out real features, such as spread $\mathrm{F}$ and sporadic $\mathrm{E}$ layers. The filtered $\mathrm{O}$ - and $\mathrm{X}$-mode traces were interpolated to matrices of fixed frequency and height resolution as required by Autoscala. Subsequently the data were saved as RDF files and automatically copied to INGV in Rome for processing. Matlab scripts for writing RDF files are available on request from the corresponding author.
Figure 2 shows an example that makes the difference between the standard O-mode real-time ionograms and the filtered RDF ionograms clear. The standard ionogram in the upper panel does show some X-mode leakage, which is disregarded in the manual scaling process. The panel below is the output from Autoscala, showing both the filtered traces and retrieved parameters. The ionospheric traces in the filtered RDF ionogram are more distinct as compared with the standard ones, but there are many additional spurious apparent echoes that look like noise. These may at least partly be due to the interpolation to the fixed range-height grid of the RDF format. An additional filtering (e.g. median filtering) could be applied to remove them, but it seems that these spurious echoes do not affect the Autoscala scaling.

\section{Results of comparison}

The Autoscala scaling was applied to SGO ionograms from the period June-December 2013: 1 June-1 July (summer solstice, ionosphere constantly sunlit), 29 July-13 October (late summer and equinox) and 1-19 December 2013 (midwinter); in total 117 days. Out of the data from these days, 2610 ionograms were analysed both manually and automatically.

\subsection{Comparison of scaled parameters}

Figure 3 presents a comparison of manually and automatically scaled parameters for 5 June 2013 (selected as an instructive case with well-defined E- and F-layer traces). The five panels in the plot represent (from top to bottom):

1. $\mathrm{M}(3000) \mathrm{F} 2$, shown by red asterisks (manual) and black circles (Autoscala);

2. F-layer O-mode critical frequencies: foF2 (red asterisks for manual and black circles for Autoscala), and foF1 (blue stars for manual and black squares for Autoscala);

3. E-layer O-mode critical frequency, foE (red asterisks for manual and black circles for Autoscala);

4. critical frequency of sporadic $E$ layers, foE $E_{\mathrm{s}}$ (red asterisks for manual and black circles for Autoscala); and

5. virtual height of sporadic $\mathrm{E}$ layers, $\mathrm{h}^{\prime} \mathrm{E}_{\mathrm{s}}$ (red asterisks for manual and black circles for Autoscala), manually scaled virtual height of $\mathrm{E}$ layer, $\mathrm{h}^{\prime} \mathrm{E}$ (blue diamonds), lower edge of $\mathrm{E}$ layer, always set to $90 \mathrm{~km}$ in Autoscala (dashed line).

Figure 3 shows a good agreement between automatically and manually scaled foF 2 and foF1. However, scaling of sporadic layers appears to be more problematic. Similar daily summaries were made for all 117 days when at least one of the 24 ionograms was scaled by Autoscala. The results are presented in Tables 1, 2 and 3 and shown as histograms in Figs. 4 and 5. 
Table 1. Number of identifications of F- and E-layer parameters, $\%$ out of in total 2610 ionograms. Auroral activity is indicated by the mean $\mathrm{AE}$ index for the cases of both manual and automatic identification and only manual identification, respectively.

\begin{tabular}{lrrrrrrr}
\hline Parameter & Manual & Auto & $\begin{array}{r}\text { Man and } \\
\text { Auto }\end{array}$ & Man only & Auto only & $\begin{array}{r}\text { Mean AE, } \\
\text { man and auto }\end{array}$ & $\begin{array}{r}\text { Mean AE, } \\
\text { man only }\end{array}$ \\
\hline foF2 and M(3000)F2 & 90.4 & 87.4 & 85.9 & 4.5 & 1.4 & 133 & 360 \\
foF1 & 35.6 & 17.6 & 16.3 & 19.3 & 1.3 & 170 & 191 \\
foE & 58.9 & 84.9 & 54.9 & 4.0 & 29.9 & 133 & 318 \\
foE $_{\mathrm{S}}$ and h' $\mathrm{h}_{\mathrm{S}}$ & 63.0 & 20.0 & 19.4 & 43.5 & 0.6 & 257 & 130 \\
\hline
\end{tabular}
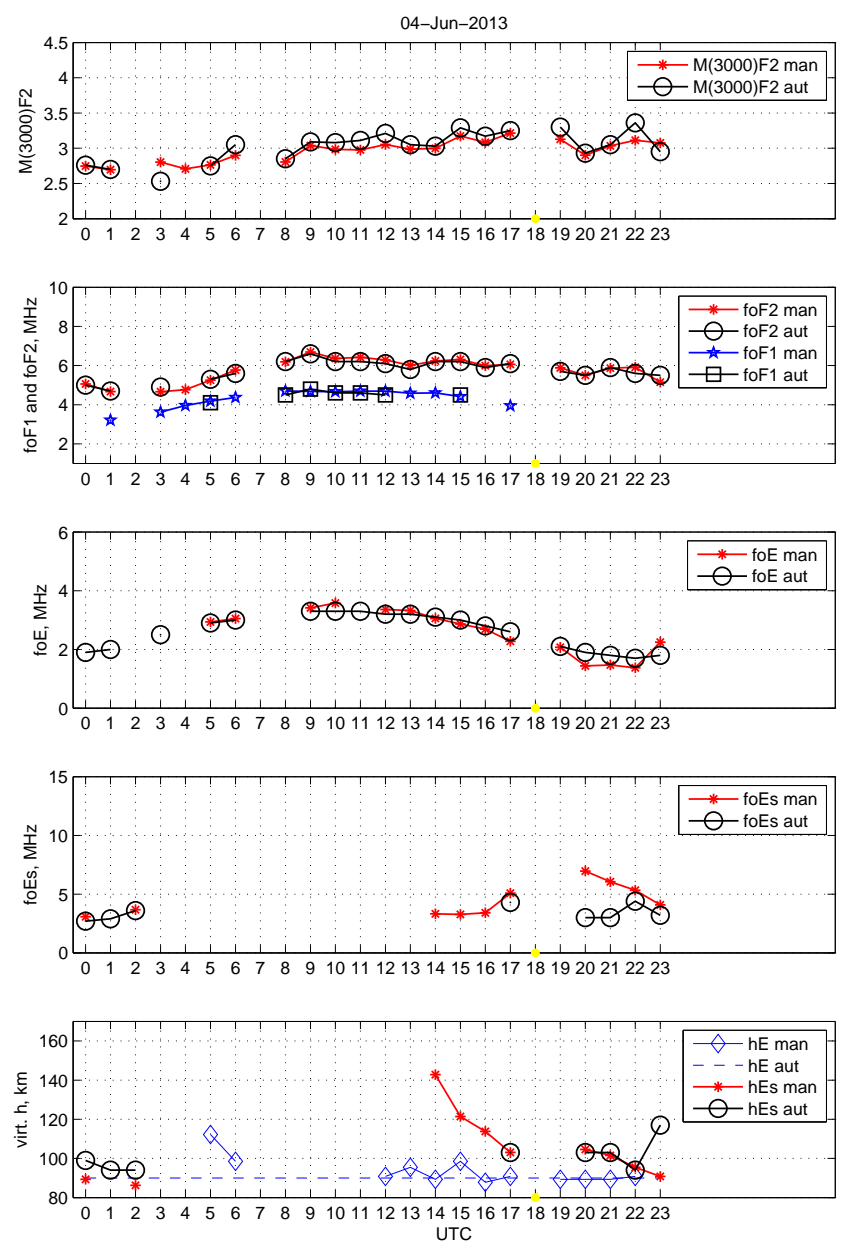

Figure 3. Comparison of manually and automatically scaled parameters for 4 June 2013. Panel 1: M(3000)F2, panel 2: F-layer O-mode critical frequencies, panel 3: foE, panel 4: foE $\mathrm{S}_{\mathrm{S}}$ and panel 5: E-layer virtual heights. Autoscala always assumes the lower edge of the $\mathrm{E}$ layer at $90 \mathrm{~km}$ (dashed line). The yellow dot on the time axis indicates a time (18:00 UT) when the ionosonde was not operating.

Table 1 presents the relative number (\%) of ionograms in which a certain parameter was identified manually, automatically, by both methods, and by one method only. The F2 layer is in general well identified by Autoscala, whereas for the other layers $\left(\mathrm{F} 1, \mathrm{E}\right.$ and $\left.\mathrm{E}_{\mathrm{s}}\right)$ the coincidence of visual and
Table 2. Differences between manually scaled and Autoscala values (manual - auto).

\begin{tabular}{lrrrr}
\hline Parameter & Mean $\pm \mathrm{SD}$ & Median & $\mathrm{Q} 1$ & $\mathrm{Q} 3$ \\
\hline$\Delta \mathrm{M}(3000) \mathrm{F} 2$ & $-0.02 \pm 0.16$ & -0.04 & -0.11 & 0.06 \\
$\Delta \mathrm{foF} 2(\mathrm{MHz})$ & $0.0 \pm 0.4$ & 0.1 & -0.1 & 0.1 \\
$\Delta \mathrm{foF} 1(\mathrm{MHz})$ & $0.1 \pm 0.1$ & 0.1 & 0.0 & 0.2 \\
$\Delta$ foE $(\mathrm{MHz})$ & $0.0 \pm 0.4$ & 0.0 & -0.2 & 0.1 \\
$\Delta$ foE $_{\mathrm{S}}(\mathrm{MHz})$ & $0.5 \pm 1.2$ & 0.6 & 0.1 & 1.0 \\
$\Delta \mathrm{h}^{\prime} \mathrm{E}_{\mathrm{S}}(\mathrm{km})$ & $-6.0 \pm 8.3$ & -3.7 & -9.3 & -0.1 \\
Manual h$^{\prime} \mathrm{E}(\mathrm{km})$ & $96 \pm 11$ & 92 & 89 & 98 \\
\hline
\end{tabular}

$\mathrm{SD}=$ standard deviation, $\mathrm{Q} 1=$ first quartile, $\mathrm{Q} 3=$ third quartile.

automatic identifications is rather low. In particular, the automatic routine identifies an $\mathrm{E}$ layer in many cases when the manual scaler does not. This happens mainly because the manual routine assumes that no E layer exists during nighttime, so for night hours (intervals depending on time of year) foE is not scaled manually at all. In such night cases the Autoscala output frequently provides a model value of foE $=0.5 \mathrm{MHz}$. Moreover, in many cases it seems that the Autoscala foE is close to prior model values for daytime as well. On the other hand, F1 and especially $\mathrm{E}_{\mathrm{S}}$ layers are frequently not identified at all by Autoscala.

The two rightmost columns in Table 1 present averaged values of the $\mathrm{AE}$ index (which characterises geomagnetic activity at auroral latitudes) for the cases when layers were identified both manually and automatically, and only manually, respectively. One may expect that under more disturbed conditions the automatic scaling works less satisfactorily. Indeed, the data in Table 1 indicate such a tendency for the F2 and E layers, namely that cases of only manual identifications occur under noticeably larger average AE conditions (360-318 nT vs. $133 \mathrm{nT}$ ). The relative number of such identifications apparently affected by auroral activity was of the order of 5-7\%. For F1 the AE dependency of automatic identification is not obvious.

Table 1 also shows that automatic identification of sporadic layers works better under disturbed conditions. However, this is not surprising. Indeed, many sporadic layers at auroral latitudes are produced by auroral precipitation, so that the most dense and distinctive $\mathrm{E}_{\mathrm{s}}$ (which are most 

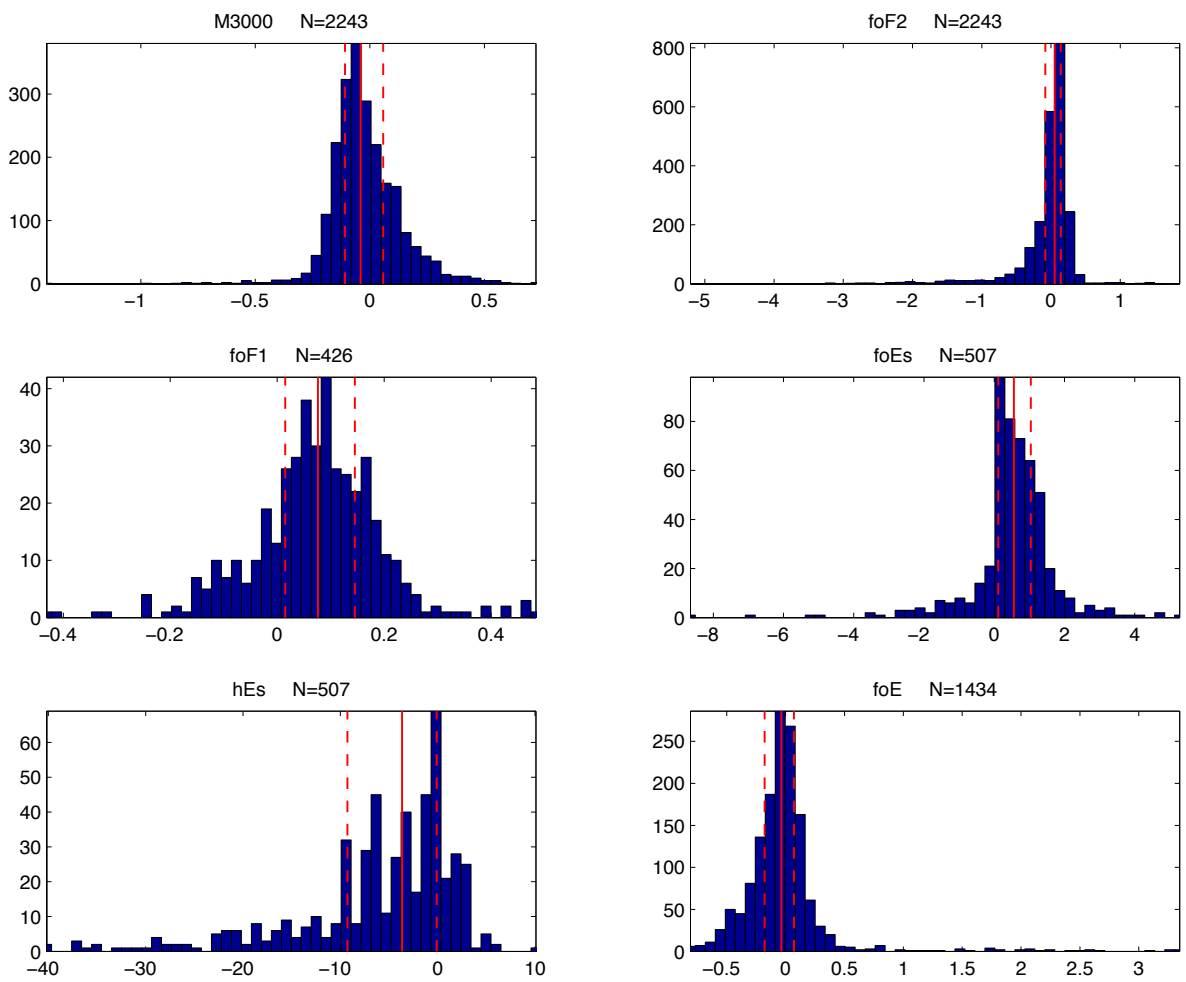

Figure 4. Distributions (histograms) of the differences between manually and automatically scaled parameters. Numbers ( $N$ ) on top of the panels indicate the numbers of ionograms for which both manual and Autoscala parameter values were obtained, and, hence, the differences were calculated. Vertical lines show medians and quartiles.

Table 3. Scaled parameters of sporadic E layers.

\begin{tabular}{|c|c|c|c|c|c|c|c|c|c|c|}
\hline \multirow[t]{2}{*}{ Type $E_{S}$} & \multirow[t]{2}{*}{$N$ man } & \multirow[t]{2}{*}{$\%$ auto } & \multicolumn{4}{|c|}{$\Delta \mathrm{foE}_{\mathrm{S}}(\mathrm{MHz})$, man - auto } & \multicolumn{4}{|c|}{$\Delta \mathrm{h}^{\prime} \mathrm{E}_{\mathrm{S}}(\mathrm{MHz})$, man - auto } \\
\hline & & & Mean \pm SD & Median & Q1 & Q3 & Mean \pm SD & Median & Q1 & Q3 \\
\hline $\mathrm{C}$ & 328 & 35 & $0.7 \pm 1.0$ & 0.7 & 0.1 & 1.0 & $-0.5 \pm 4.5$ & 0.1 & -1.3 & 1.6 \\
\hline $\mathrm{H}$ & 244 & 7 & $0.6 \pm 0.6$ & 0.4 & 0.1 & 0.8 & $0.2 \pm 2.6$ & 0.7 & -2.6 & 1.8 \\
\hline $\mathrm{L}$ & 373 & 25 & $0.4 \pm 1.2$ & 0.4 & 0.0 & 1.0 & $-5.4 \pm 4.8$ & -6.2 & -9.3 & -1.6 \\
\hline $\mathrm{F}$ & 128 & 41 & $0.5 \pm 1.3$ & 0.5 & 0.1 & 1.1 & $-4.2 \pm 6.7$ & -3.2 & -6.2 & -0.1 \\
\hline A & 105 & 19 & $0.2 \pm 1.4$ & 0.5 & 0.1 & 0.8 & $-14.5 \pm 11$ & -13.0 & -25.7 & -4.7 \\
\hline $\mathrm{R}$ & 389 & 43 & $0.6 \pm 1.3$ & 0.7 & 0.3 & 1.2 & $-9.5 \pm 9.1$ & -6.9 & -13.7 & -3.2 \\
\hline $\mathrm{K}$ & 79 & 53 & $0.0 \pm 1.1$ & 0.3 & -0.3 & 0.6 & $-9.5 \pm 8.8$ & -8.9 & -15.4 & -1.6 \\
\hline
\end{tabular}

$\mathrm{SD}=$ standard deviation, $\mathrm{Q} 1=$ first quartile, $\mathrm{Q} 3=$ third quartile.

easily detected by Autoscala) occur during disturbed conditions. On the other hand, an experienced scaler may notice less prominent, weaker layers during more quiet conditions, which are not identified by the automatic scaling.

Some examples of erroneous identifications and possible reasons will be discussed further in Sect. 5.3.

Table 2 presents statistics of the differences between the manually and automatically scaled values of all parameters. In the bottom row we present only manually scaled $\mathrm{h}^{\prime} \mathrm{E}$, since Autoscala always assumes the height to be $90 \mathrm{~km}$. These results are also illustrated by histograms in Figs. 4 and 5, where Fig. 4 shows the distributions of the differences between manually and automatically scaled parameter values with medians and quartiles, and Fig. 5 shows the distribution of manually scaled $\mathrm{h}^{\prime} \mathrm{E}$ values and the fixed height of $90 \mathrm{~km}$ assumed by Autoscala. The distribution of manually scaled values has its most probable value close to $90 \mathrm{~km}$ as well, so the assumption is reasonable, but there is a long tail of $\mathrm{h}^{\prime} \mathrm{E}$ observations well above $100 \mathrm{~km}$. It will be seen that the occurrence of such $\mathrm{E}$ layers presents a problem.

The results can be summarised as follows: 


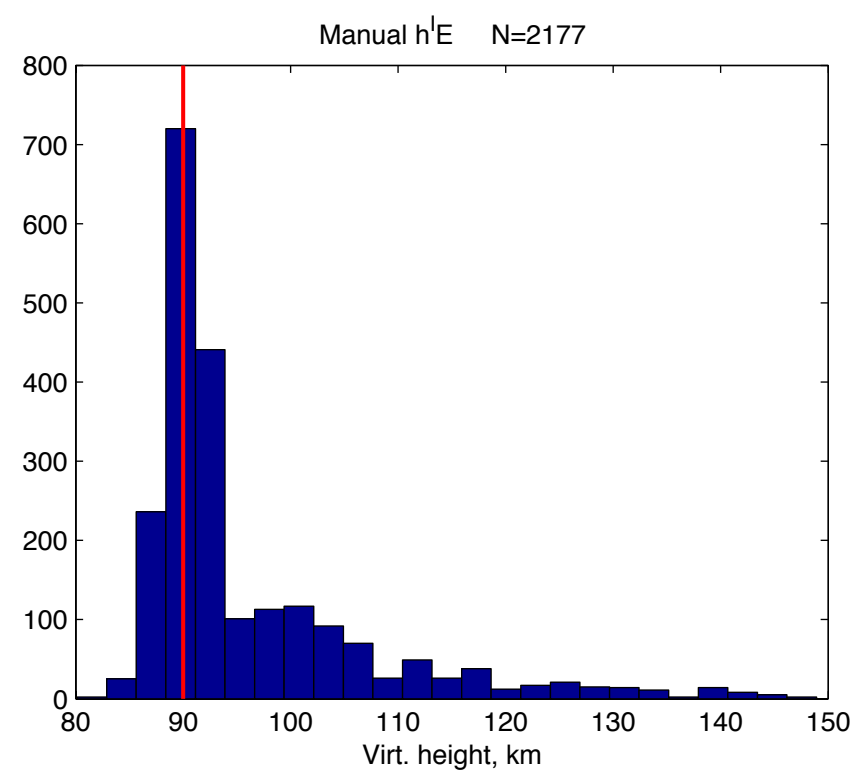

Figure 5. Distribution of $h^{\prime} E$ scaled manually. The red line at $90 \mathrm{~km}$ indicates the fixed height assumed in Autoscala. The mode of the manually scaled $\mathrm{h}^{\prime} \mathrm{E}$ distribution is close to $90 \mathrm{~km}$ as well.

- Generally, there is a very good agreement between the manually and automatically scaled $\mathrm{F} 2$ parameters, foF2 and $\mathrm{M}(3000) \mathrm{F} 2$. They were identified by Autoscala in $86 \%$ of the cases with an accuracy of $0.4 \mathrm{MHz}$ and 0.16 units, respectively.

- The F1 layer was detected by Autoscala in only about half of those cases when it was identified manually. In the cases of detection, however, the values of foF1 were reliable within an accuracy of $0.1 \mathrm{MHz}$.

- For E, the foE values from Autoscala were within $0.4 \mathrm{MHz}$ of those obtained manually when scaled. Autoscala identifies foE in many cases $(30 \%$ of all ionograms) when no E layer was identified by the manual scaling. See also an example in Sect. 5.3 below.

- Sporadic E layers $\left(E_{s}\right)$ were identified by Autoscala in relatively few cases (about one-third of the manual detections). The difference between manually and automatically scaled parameters may be significant.

It thus appears that sporadic $\mathrm{E}$ layers are the most difficult to scale automatically. In the next section this is considered in more detail.

\subsection{Scaling of sporadic E layers}

$\mathrm{E}_{\mathrm{S}}$ layers (e.g. Turunen and Rao, 1976) are typically caused by metallic ions. In the auroral oval, however, there are additional specific sporadic layers caused by auroral ionisation. Since auroral precipitation varies rapidly both in intensity and horizontal localisation within the timescale of typical ionosoundings (even the 1 min resolution of Alpha Wolf), and is also often followed by strong D-layer absorption preventing the observation of higher layers, the scaling of sporadic $\mathrm{E}$ layers at auroral latitudes is often a difficult task.

Sporadic E layers are classified by assigning them to one or more of the following types according to the shape and strength (blanketing of higher layers) of the trace. More than one type can be observed in a single ionogram and in these cases foE $E_{\mathrm{s}}$ and $\mathrm{h}^{\prime} \mathrm{E}_{\mathrm{s}}$ are given for the layer with maximal $\mathrm{foE}_{\mathrm{s}}$. The rules for classification are described in detail in the URSI handbook of ionogram interpretation (Piggott and Rawer, 1978).

\subsubsection{Mid-latitude types}

The following types of sporadic E layers are those which can be observed at subauroral latitudes. They can occur everywhere, however. The list does not include the equatorial type $(q)$ which is only seen close to the magnetic equator.

- C (cusp) is an $E_{s}$ trace showing a relatively symmetrical cusp at or below the critical frequency of the normal $\mathrm{E}$ or particle $\mathrm{E}$ layer.

- $\mathrm{H}$ (high) is an $\mathrm{E}_{\mathrm{s}}$ trace showing a discontinuity in height with the normal $\mathrm{E}$ or particle E-layer trace at or above the critical frequency. The cusp is not symmetrical.

- L (low) is a flat $E_{s}$ trace below the normal $E$ or particle E minimum virtual height.

- F (flat) is a clean $E_{s}$ trace which shows no appreciable increase of height with frequency. Only applicable when no values of foE are obtainable (i.e. during nighttime). At other hours, similar $\mathrm{E}_{\mathrm{S}}$ traces are classified as L, C or $\mathrm{H}$.

\subsubsection{High-latitude types}

The following types of sporadic E layers occur as a result of particle precipitation.

- $R$ (retardation) is an $E_{S}$ trace showing an increase in virtual height at the high frequency end but which becomes partially transparent below foE $\mathrm{E}_{\mathrm{s}}$.

- K (particle) denotes the presence of a particle E layer, similar in appearance to normal E, which obscures higher layers up to its critical frequency.

- A (auroral) denotes all types of very spread $E_{s}$ traces typical of oblique reflections from structures that are both small in spatial scales and varying rapidly in time as compared with the sounding time. The typical pattern shows a well-defined flat or gradually rising lower edge with stratified or diffuse traces present above it. 


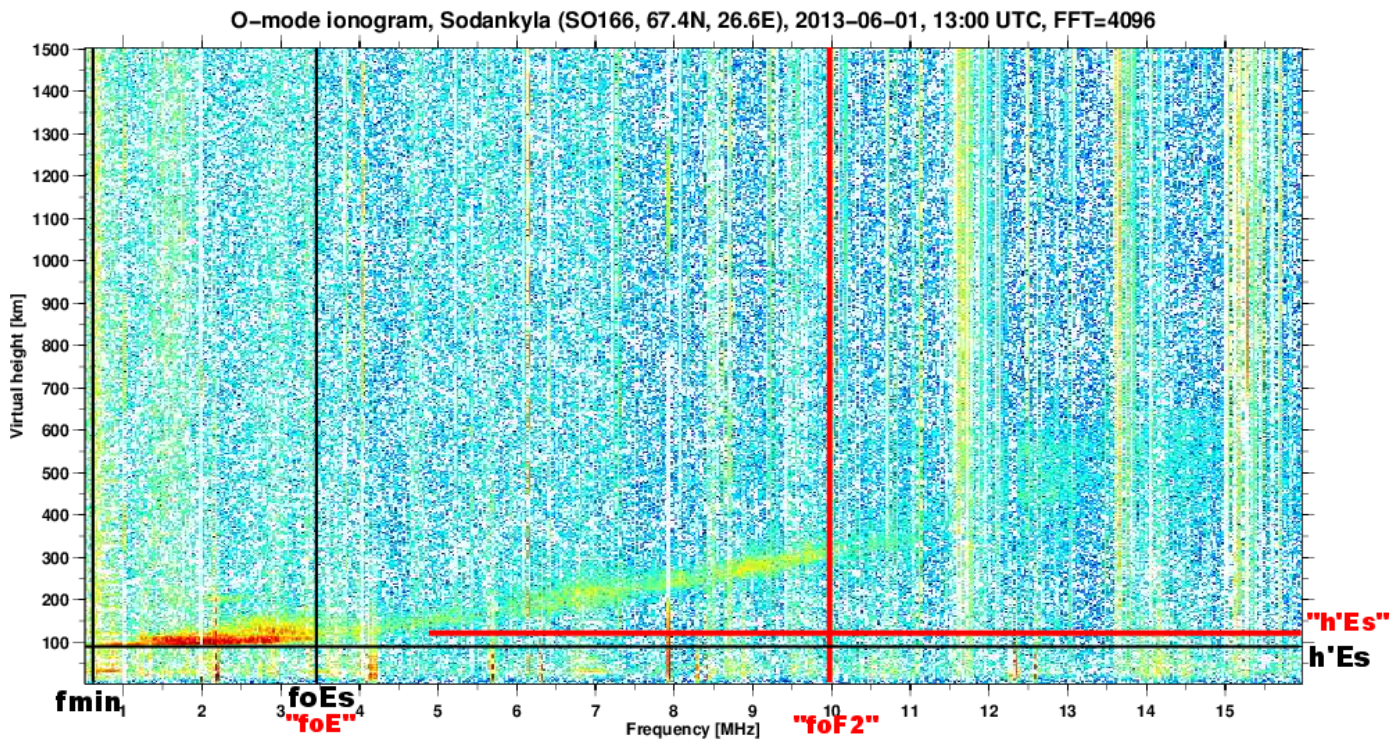

Figure 6. Differences between manual and Autoscala scaling arising from high latitude sporadic E phenomena. Black lines show manually scaled parameters, and red colour (lines and/or letter) indicates Autoscala results. Example 1: foE $\mathrm{S}_{\mathrm{S}}$ identified as foE, and the slant $\mathrm{E}_{\mathrm{S}}(\mathrm{type} \mathrm{S}$ ) identified as an $\mathrm{F}$ layer.

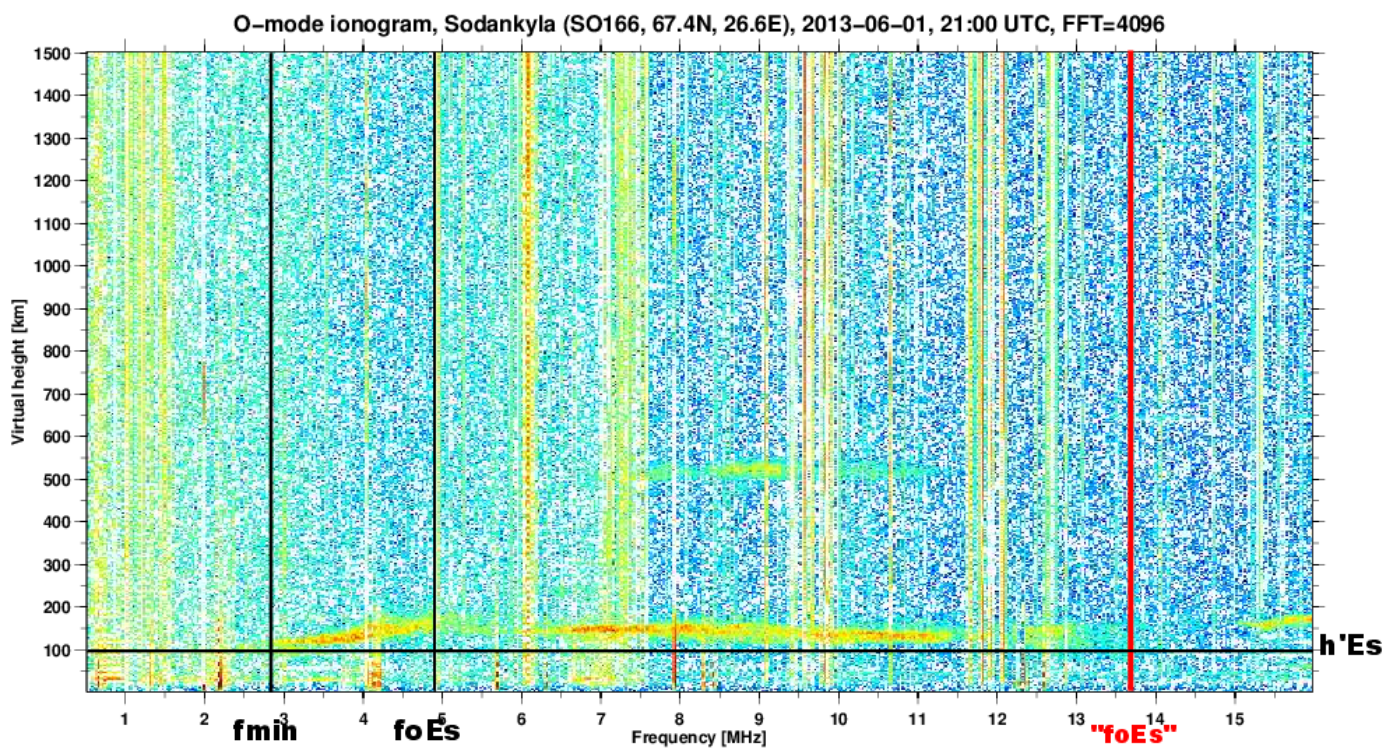

Figure 7. Differences between manual and Autoscala scaling arising from high latitude sporadic E phenomena. Black lines show manually scaled parameters, and red colour (lines and/or letter) indicates Autoscala results. Example 2: overestimated foE $(13.7 \mathrm{MHz}$ vs. manual 4.9 MHz).

\subsubsection{Indicated but not scaled}

- S (slant) is a diffuse $E_{S}$ trace whose virtual height rises steadily with frequency.

- D (D layer) is not strictly a sporadic E layer but a weak diffuse trace at or below $95 \mathrm{~km}$ associated with high absorption and consequently high $f_{\min }$.
In Table 3, we present a comparison of manual and Autoscala parameters separately for each type of $E_{s}$. The first three columns in the left present types of $E_{s}$, numbers of manual identifications and percentage of Autoscala identifications. Then, averaged differences between manually and automatically scaled values are presented as mean values with standard deviations and median values with upper and lower quartiles. 


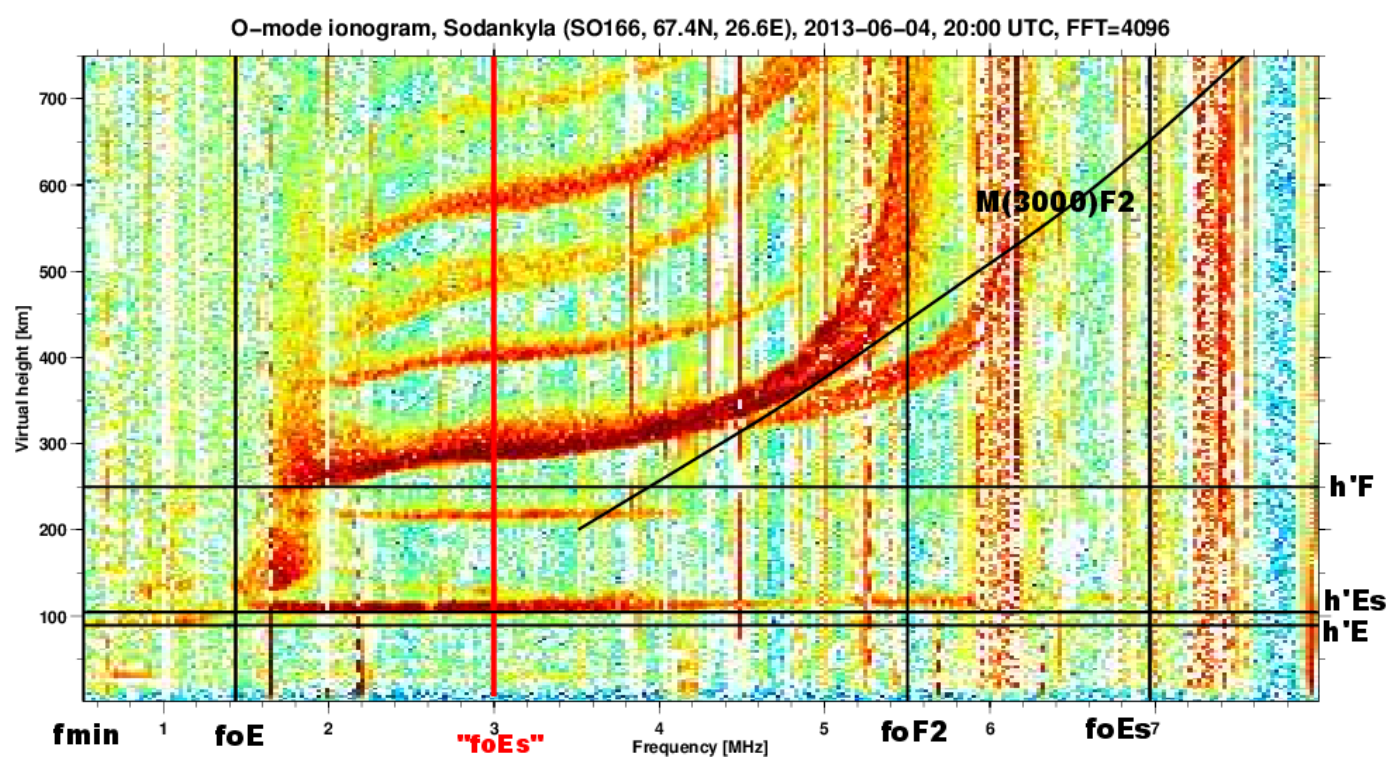

Figure 8. Differences between manual and Autoscala scaling arising from high latitude sporadic E phenomena. Black lines show manually scaled parameters, and red colour (lines and/or letter) indicates Autoscala results. Example 3: Underestimated foE $\mathrm{s}_{\mathrm{s}}(3.0 \mathrm{MHz}$ vs. manual 7.0 MHz)

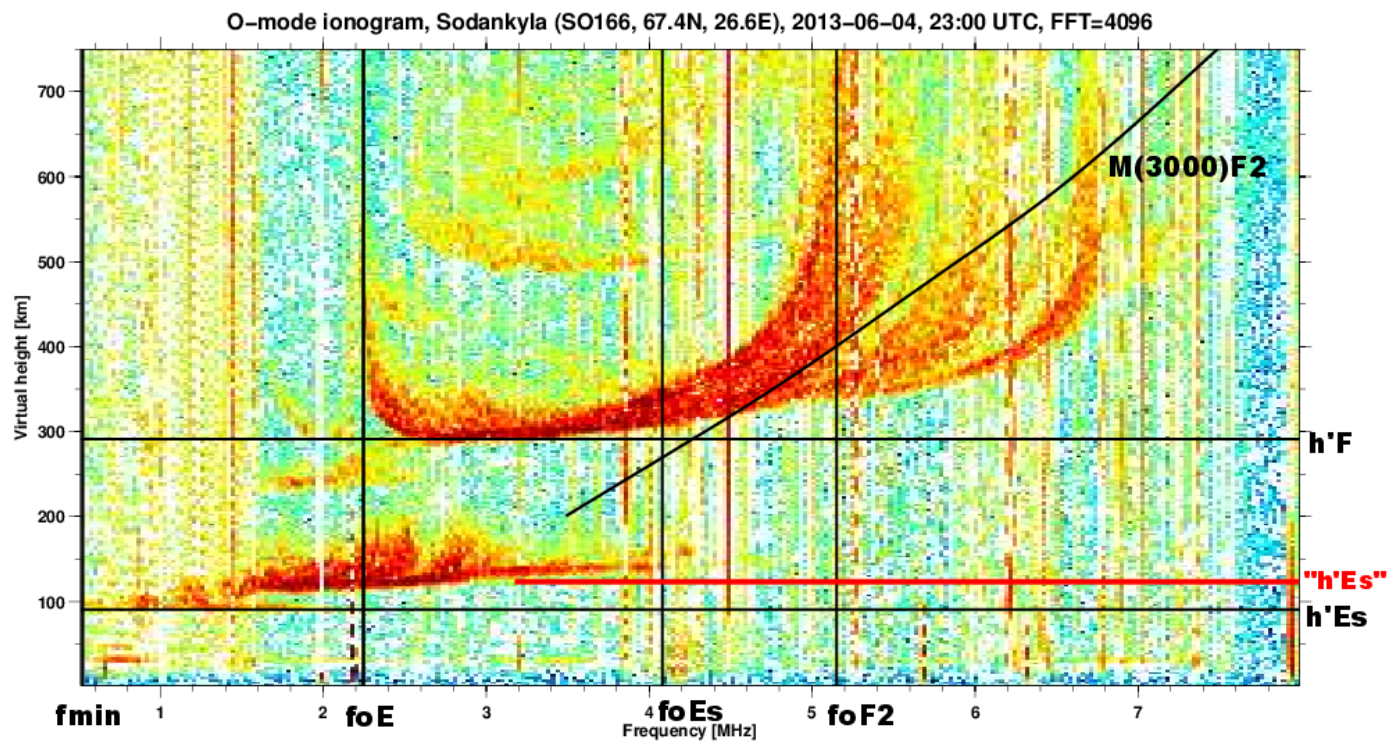

Figure 9. Differences between manual and Autoscala scaling arising from high latitude sporadic E phenomena. Black lines show manually scaled parameters, and red colour (lines and/or letter) indicates Autoscala results. Example 4: Error in $\mathrm{h}^{\prime} \mathrm{E}_{\mathrm{S}}$ scaling (117 km vs. manual $91 \mathrm{~km})$.

From Table 3 it is evident that $\mathrm{K}, \mathrm{R}$ and $\mathrm{F}$ types were better recognised by Autoscala, whereas the $\mathrm{H}$ type was seldom identified. Autoscala typically underestimates foE $_{\mathrm{s}}$ by about $0.5 \mathrm{MHz}$, and the virtual height is typically overestimated, especially for the high-latitude type $\mathrm{E}_{\mathrm{S}}$ (up to the order of $10 \mathrm{~km})$.

\subsection{Examples of problems}

Scaling of high-latitude ionograms is often difficult even for an experienced scaler, due to phenomena such as particle precipitation and oblique reflections. A comprehensive consideration of particular cases is beyond the scope of the present paper, but to illustrate possible problems we present a few examples in Figs. 6, 7, 8 and 9 that point out differences between manual and Autoscala scaling. In these ionograms 
black lines show manually scaled parameters, and red colour (lines and/or letters) indicates Autoscala results.

In Fig. 6, foE $\mathrm{E}_{\mathrm{s}}$ (scaled manually at $3.5 \mathrm{MHz}$ ) was identified as foE. The foE $E_{\mathrm{s}}$ value was automatically detected at $4.8 \mathrm{MHz}$ and $\mathrm{h}^{\prime} \mathrm{E}_{\mathrm{s}}$ was detected near $126 \mathrm{~km}$. The slant $\mathrm{E}_{\mathrm{S}}$ (type $\mathrm{S}$ ) was identified as an F layer with foF $2=9.9 \mathrm{MHz}$. In Fig. 7, the manually scaled foE $\mathrm{E}_{\mathrm{S}}$ is $4.9 \mathrm{MHz}$, whereas $\mathrm{Au}-$ toscala finds foE $_{\mathrm{s}}=13.7 \mathrm{MHz}$. One more example of foE difficulties is given in Fig. 8, where the Autoscala value is $3.0 \mathrm{MHz}$, whereas the manually scaled value is $7.0 \mathrm{MHz}$. Figure 9 shows an example of $h^{\prime} E_{s}$, identified manually at $91 \mathrm{~km}$ and by Autoscala at $117 \mathrm{~km}$.

However, with regard to this issue it is worth underlining the two following points:

1. The Autoscala routine for autoscaling the $\mathrm{E}_{\mathrm{s}}$ layer is designed mostly for mid-latitude ionograms (Scotto and Pezzopane, 2007).

2. The filtering process applied when generating RDF ionograms from raw SGO Alpha Wolf ionosonde data often causes a deletion of significant parts of the ionogram trace, especially those related to spread $\mathrm{F}$ and $\mathrm{E}_{\mathrm{s}}$ features. Although improving the contrast of normal $\mathrm{E}$ and $\mathrm{F}$ traces, this clearly affects the ability of the Autoscala $\mathrm{E}_{\mathrm{S}}$ routine.

\section{Conclusions}

In summary, this comparison between manual and Autoscala scaling of ionograms at the high-latitude Sodankylä Geophysical Observatory site has shown that:

1. The F2 parameters (foF2 and $\mathrm{M}(3000) \mathrm{F} 2$ ) were identified by Autoscala in $86 \%$ of the manually identified cases, within $0.4 \mathrm{MHz}$ and 0.16 units, respectively.

2. F1 is identified by Autoscala in significantly fewer cases (about 50\%) than manually identified, but when identified the values of foF1 were reliable within $0.1 \mathrm{MHz}$.

3. E-layer parameters found by Autoscala are close to the manually scaled ones when those are scaled, foE agreeing within an accuracy of $0.4 \mathrm{MHz}$. However, Autoscala detects $\mathrm{E}$ layers in many cases when the manual scaling process either does not identify one or assumes that none exist during nighttime.

4. The identification and classification of sporadic E layers are in many cases very different from those of the manual scaling.

Scaling of ionograms at auroral latitudes is, in many cases, a demanding task. Often there are multiple oblique echoes from different ranges which show up as spread traces, and another difficulty is presented by the frequent sporadic E layers caused by auroral precipitation. Energetic particle precipitation also sometimes causes D-layer absorption that blankets $\mathrm{E}$ and $\mathrm{F}$ echoes. This makes automatic scaling less straightforward as compared to scaling of ionograms from mid latitudes. More studies, including scaling of ionograms processed from the raw recorded data with different FFT and filter parameters, will be required in order to find optimal settings for the contrast of normal $\mathrm{E}$ and $\mathrm{F}$ traces, which is a tradeoff with the detectability of sporadic $\mathrm{E}$ and spread F.

Acknowledgements. Carl-Fredrik Enell and Alexander Kozlovsky acknowledge support from the project Near-Earth Space Data Infrastructure for E-Science (ESPAS), which received funding from the European Union's Seventh Framework Programme for research, technological development and demonstration under grant agreement number 283676.

Carl-Fredrik Enell is now at EISCAT Scientific Association, an international research organisation funded by the following institutes (the EISCAT Associates): China Research Institute of Radiowave Propagation, People's Republic of China; National Institute of Polar Research, Japan; Norges forskningsråd, Norway; Natural Environment Research Council, UK; Solar-Terrestrial Environment Laboratory, Nagoya University, Japan; Suomen Akatemia, Finland; and Vetenskapsrådet, Sweden.

Edited by: N. Partamies

\section{References}

Bullett, T., Malagnini, A., Pezzopane, M., and Scotto, C.: Application of Autoscala to ionograms recorded by the VIPIR ionosonde, Adv. Space Res., 45, 1156-1172, 2010.

Eaton, J. W. et al.: GNU Octave, http://www.octave.org (last access 17 March 2016), version 3.2.4, 2009.

Galkin, I. A. and Reinisch, B. W.: The new ARTIST 5 for all digisondes, Ionosonde Network Advisory Group Bull., 69,1-8, http://www.ips.gov.au/IPSHosted/INAG/web-69/2008/ artist5-inag.pdf, 2008.

Kozlovsky, A., Turunen, T., and Ulich, T.: Rapid-run ionosonde observations of traveling ionospheric disturbances in the auroral ionosphere, J. Geophys. Res., 118, 5265-5276, 2013.

Krasheninnikov, I., Pezzopane, M., and Scotto, C.: Application of Autoscala to ionograms recorded by the AIS-Parus ionosonde, Comput. Geosci., 36, 628-635, 2010.

Pezzopane, M. and Scotto, C.: Software for the automatic scaling of critical frequency foF2 and MUF(3000)F2 from ionograms applied at the Ionospheric Observatory of Gibilmanna, Ann. Gephys., 47, 1783-1790, 2004.

Pezzopane, M. and Scotto, C.: The INGV software for the automatic scaling of foF2 and MUF(3000)F2 from ionograms: a performance comparison with ARTIST 4.01 from Rome data, J. Atmos. Sol.-Terr. Phys., 67, 1063-1073, 2005.

Pezzopane, M. and Scotto, C.: Automatic scaling of critical frequency foF2 and MUF(3000)F2: A comparison between Autoscala and ARTIST 4.5 on Rome data, Radio Sci., 42, RS4003, doi:10.1029/2006RS003581, 2007. 
Pezzopane, M. and Scotto, C.: A method for automatic scaling of F1 critical frequencies from ionograms, Radio Sci., 43, 2, RS2S91, doi:10.1029/2007RS003723, 2008.

Pezzopane, M. and Scotto, C.: Highlighting the F2 trace on an ionogram to improve Autoscala performance, Comput. Geosci., 36, 1168-1177, 2010.

Pezzopane, M., Zuccheretti, E., Bianchi, C., Scotto, C., Zolesi, B., Cabrera, M. A., and Ezquer, R. G.: The new ionospheric station of Tucumán: First results, Ann. Geophys., 50, 483-492, 2007.

Pezzopane, M., Scotto, C., Stanislawska, I., and Juchnikowski, G.: Ionosonde Network Advisory Group Bulletin, chap. Autoscala applied at the Ionospheric Station of Warsaw, 69, IPS Radio and Space Serv., Surry Hills, N. S. W., Australia, http://www.sws. bom.gov.au/IPSHosted/INAG/web-69/2008/inag_warsaw.pdf (last access: 8 March 2016), 1-6, 2008.

Pezzopane, M., Scotto, C., Tomasik, L., and Krasheninnikov, I.: Autoscala: an aid for different ionosondes, Acta Geophys., 58, 513526, 2010.

Piggott, W. R. and Rawer, K., (Eds.): U. R. S. I. handbook of ionogram interpretation and reductions, vol. 23A of $U A G$, World Data Center A for Solar-Terrestrial Physics, 1978.

Reinisch, B. W., Galkin, I. A., Khmyrov, G. M., Kozlov, A. V., Bibl, K., Lisysyan, I. A., Cheney, G. P., Huang, X., Kitrosser, D. F., Paznukhov, V. V., Luo, Y., Jones, W., Stelmash, S., Hamel, R., and Grochmal, J.: New Digisonde for research and monitoring applications, Radio Sci., 44, RS0A24, doi:10.1029/2008RS004115, 2009.
Rietveld, M. T., Wright, J. W., Zabotin, N., and Pitteway, M. L. V.: The Troms $\emptyset$ dynasonde, Polar Science, 2, 55-71, 2008.

Scotto, C.: Electron density profile calculation technique for Autoscala ionogram analysis, Adv. Space Res., 44, 756-766, 2009.

Scotto, C. and MacDougall, J.: Application of Autoscala software to the Canadian Advanced Digital Ionosonde, Int. J. Remote Sensing, 33, 5574-5582, 2012.

Scotto, C. and Pezzopane, M.: A method for automatic scaling of sporadic E layers from ionograms, Radio Sci., 42, RS2012, doi:10.1029/2006RS003461, 2007.

Scotto, C. and Pezzopane, M.: Removing multiple reflections from the F2 layer to improve Autoscala performance, J. Atmos. Sol.Terr. Phys., 70, 1929-1934, 2008.

Scotto, C., Pezzopane, M., and Zolesi, B.: Estimating the vertical electron density profile from an ionogram: On the passage from true to virtual heights via the target function method, Radio Sci., 47, RS1007, doi:10.1029/2011RS004833, 2012.

Turunen, T. and Rao, M. M.: Statistical behaviour of sporadic E in Sodankylä 1958-1971, Geophysica, 14, 77-98, 1976.

Wakai, N., Ohyama, H., and Koizumi, T.: Manual of Ionogram Scaling, Radio Research Laboratory, Ministry of Posts and Telecommunications, Japan, 3rd Edn., 1987. 